\title{
Activity and Profile of the Forensic Psychiatrist
}

\author{
Anamaria Ciubară, Bogdan Alexandru Ciubară, Roxana Chiriță, Lucian Ștefan Burlea, \\ Ilinca Untu, Diana Bulgaru Iliescu
}

University of Medicine and Pharmacy GR. T. POPA, Iași, Roumania

Email: ilinca tzutzu@yahoo.com

Received January 2015

\begin{abstract}
The criminality amongst psychiatric patients is a subject of interest nowadays and wide social phenomenon which requires a thorough, multidisciplinary assessment of the patient that committed a crime. The role of the forensic psychiatrist is to establish the patient's judgement by evaluating his behavior, considering first and foremost his personal experience regarding psychiatric pathology. His evaluation is fundamental in establishing if the patient knows right from wrong, if he acted deliberately and conscious or because of certain psychiatric disorders that abolish his judgement. The forensic psychiatrists have the obligation to know the rules and legislation, to be trustworthy and proficient. They have the mission to ascertain the information given by the patient in order to be used by the legal system. The current study aims to realise a synthesis regarding the features of activity and the forensics psychiatrist profile.
\end{abstract}

\section{Keywords}

Forensic Psychiatrist, Psychopathology, Social Wellbeing, Objectivity

\section{Introduction}

Psychiatry is in fact tributary because of its theoretical and explanatory essence to the concepts that tries to tackle the human behaviour. Psychiatry is a strict discipline, especially in terms of its applicability, because of the complex human behavior [1] [2].

Semantically, the expertise is a scientific research done in technical manner, by an expert at the request of a court or judicial body, on certain legal aspects. Forensic psychiatry is a mainstreaming, analytical act that helps justice in its role to establish the truth [2] [3].

The objective of the forensic psychiatry is the criminal behaviour of the psychiatric patient, the psychopathological delinquency and the patients' capability of society integration. The purpose of forensic psychiatry is to carefully evaluate the patient's behaviour and mental state in order to help the law to establish the patient guilt/responsibility or his capability to function in a society [1] [4].

Judgement, the expertise's goal, is the specific application of the general notion of mental capacity in the concrete situation of a deed, subject expertise [5]. 
The current paper aims to realise a synthesis regarding the activity of the forensics psychiatrist, taking into account the fundamental differences between the standard doctor-patient relationship and the one between the forensic expert and his patient and keeping in mind that the good of society comes first.

\section{Generalities Regarding the Forensics Psychiatrists Activity}

The forensic psychiatrists cooperate with the justice system, assessing the patient's competency to stand trial, make recommendations to the judge and also can defend the accused/patient, based on the possible psychiatric pathologies that can interfere with his judgment [1] [5].

The forensic psychiatric assessment focuses on two major objectives. The first is the ability to establish the patients capability who committed a crime, to appear in court while the other aims to assess the patient's mental state at the time of the deed. The latter offers the court an expert opinion on the patient's mental state at the time of committing the offense, focusing on the ability of the defendant/patient to understand their act and its consequences [1] [4] [6].

Forensic psychiatrists are often called as experts in both criminal or civil proceedings, to be part of a committee and to participate as an expert witness in court. Forensic Psychiatrists are also involved in the treatment and care of patients who have committed crimes and are incarcerated in prisons but also for treating the psychiatric patients who committed a criminal act, without any discernment at the time, and are hospitalized in a maximum security hospital [1] [3] [7].

The forensic psychiatry practice raises a number of ethical problems. Fundamental is unclear boundary between the psychiatrist's as a physician and an expert in forensic psychiatry. Thus, it brings into focus the probability damage doctor-patient relationship is where the psychiatrist and expert clinician for his patients. The forensic psychiatry practice raises a number of ethical issues. Very important is the unclear boundary between the psychiatrist as a physician and also being a forensic expert [1] [8]. Thus, it brings into focus the probability of damaging the doctor-patient relationship in cases where the psychiatrist is a physician and forensic expert for his patients [2].

In this context, the current guidelines suggest that the psychiatrist that is also physician for his patients to avoid accepting the position of expert witness in their trials. It can culminate to a real distortion of justice and even a disrespect towards the profession itself if the psychiatrist appears in court for his patients. Hence the ambiguity that can arise regarding the ethical and intellectual boundaries of the forensic psychiatry. Thus, fairness and honesty are the ideal moral profile of forensic psychiatrist, which can not be obtained if he is to circumvent the rule of being both therapist and expert for the same patient [1] [5].

\section{Moral Profile of the Forensic Psychiatrist and the Rigors of His Practice}

The current guidelines of practice in forensic psychiatry support the respect of objectivity and neutrality as "sine qua non" values. Also, is fundamental to preserve the autonomy of the examiner (forensic psychiatrist), and his anonymity. Consequently, it must be protected the confidentiality of the forensic assessment. The time and length of the forensic psychiatric assessment must be established from the very beginning and respected as strictly as possible, the expertise having a small but well defined fee. The forensic psychiatrist must avoid any personal relationships with their patient both now and in the future, and also proving that he has no link with the patient in the past. It is fundamental to obtain the informed consent of the patient who is subject to expertise, except where the expertise is required by law [1] [6].

In the context of mental health, from a perspective point of view, the forensic psychiatrists operate outside the standard medical care, the ethical principles underlying their professional conduct not overlap the traditional doctor-patient relationship aspect. The patient benefit is counterbalanced by the benefit of the society, which can cause a number of ethical dilemmas. It derives precisely from confronting the patient wellbeing with society's welfare, by the latter meaning public safety. The mandatory protection of the people represent the start of non-voluntary treatment. If the psychiatrist reveals a potential threat to public safety, from the patient, he has an obligation to the people's wellbeing instead of the patient [6] [8] [9].

The International Code of Medical Ethics states that a physician must act solely in the interest of the patient when performing a medical act which could have an adverse effect on the somatic or mental condition of the patient [9].

On the other hand, the forensic psychiatry practice guidelines demand that the forensic psychiatrists assess- 
ment to be realised in a spirit of honesty and in a complete and utter objectivity.

It therefore emphasized the difference between the traditional ethics of a doctor-patient relationship, in the absence of a forensic expertise, and the ethical implications of the forensic psychiatrist as a legal expert on forensic psychiatry [1] [8].

International guidelines for forensic psychiatrist establish three main obligations of the forensic psychiatrist, which are to provide an objective assessment, to maintain the confidentiality imposed by the law and to disclosure any existing or potential conflict of interest that could jeopardize the quality of the forensic expertise [6].

The forensic psychiatry should take into account the same rules and moral principles as general medicine, but there are some peculiarities that address strictly the forensic psychiatrists. Thus, they do not act primarily for the benefit and interest of the patient when an expertise, by a legal body, is called for. These surveys do not always serve the patient's medical sake and in many cases their result may harm the non-medical interests of the patient [4] [9].

\section{Conclusions}

General psychiatry provides doctors who work as forensic psychiatrists. They are psychiatrists who participate as expert witness in court, conduct forensic work in general psychiatric hospitals or in hospitals for maximum security.

Given this context, that balances the requirement to provide an impartial and neutral opinion about patient from a forensic expert and that of being honest, fair and good towards the patient as a physician. Here it is extremely important to set a bound between the role of a physician and an expert.

In the context of forensic psychiatry, the relationship between the psychiatrist and the individual is characterized by the interference of a third party, represented by the justice, for which the psychiatrist has a legal and moral duty. The forensic psychiatrist puts the patients interests second and the truth and the social wellbeing first. The forensic Psychiatrist's mission is a complex and a highly demanding one, led by strict moral standards very different from the rules that guide the classic psychiatrist-patient relationship.

\section{References}

[1] Bulgaru Iliescu, D., Costea, G., Oprea, L., Gheorghiu, V., Enache, A. and Astărăstoae, V. (2013) Forensic Psychiatrycal Expertise (Expertiza Medico-Legală Psihiatrica in Roumanian), ed. Timpul, 723-748.

[2] Velinov, V.T. and Marinov, P.M. (2006) Forensic Psychiatric Practice: Worldwide Similarities and Differences. World Psychiatry, 5, 98-99.

[3] Wettstein, R.M. (2002) Ethics and Forensic Psychiatry. Psychiatric Clinics of North America, 25, 623-633. http://dx.doi.org/10.1016/S0193-953X(02)00007-2

[4] Rosner, R. (2003) A Conceptual Framework for Forensic Psychiatry. In: Rosner, R., Ed., Principles and Practice of Forensic Psychiatry, 2nd Edition, Arnold, UK. http://dx.doi.org/10.1201/b13499-3

[5] American Psychiatry Association (2001) Opinions of the Ethics Committee on the Principles of Medical Ethics with Annotations Especially Applicable to Psychiatry and Forensic Psychiatry. APA, Washington DC.

[6] Diamond, B.L. (1992) The Forensic Psychiatrist: Consultant versus Activist in Legal Doctrine. Bulletin of the American Academy of Psychiatry and the Law, 20, 119-131.

[7] Declaration on Bioethics and Human Rights, Universal Draft, Paris, 24 June 2005. www.unesco.or/shsbioethics

[8] Bluglass, R., Bauden, P. and Wilker, N. (1990) Principles and Practice of Forensic Psychiatry. Churchill Livingstone, Edinburgh.

[9] American Academy of Psychiatry and the Law (2005) Ethics Guidelines for the Practice of Forensic Psychiatry. 